\title{
The effects of selected factors on regional road fatalities - analysis of the Łódź region
}

\author{
Joanna Wachnicka ${ }^{1}$, Marcin Budzyński ${ }^{1 *}$, Wojciech Kustra $^{1}$ and Anna Gobis ${ }^{1}$ \\ ${ }^{1}$ Gdansk University of Technology, Narutowicza 11/12, 80-233 Gdansk, Poland
}

\begin{abstract}
Analysis of regional accident records shows that a country's national road safety programme does not have the same effect in each of its regions. What may be a serious problem in one region may be of marginal significance in another. Polish and international experience shows that main risk groups and types of accidents related to the level of development and quality of the road network differ from region to region. The conclusion is that a centrally run road safety policy does not always produce the expected outcomes. This suggests that more can be achieved with a combination of strategic (national) road safety management and tactical (regional) and operational (local) road safety efforts. Poland's regional road safety programmes were found to lack an analysis of the effects of selected factors on safety or fatality forecast based on mathematical models. This calls for a scientific tool to support regional road safety management. The article uses the example of the region of Łódź to present the main road safety problems, analyse safety based on risk assessment, present the effects of selected factors on road user safety and forecast fatalities for different scenarios of treatments.
\end{abstract}

\section{Introduction}

Poland continues to be the European Union's worst performing country for its number of road fatalities compared to its population. In 2017 there were 2,831 people killed on Polish roads with 39,466 injured (including 11,103 serious injuries). The demographic fatality rate was 7.3 fatalities per 100,000 population which is twice as bad as in the best performing countries (the Netherlands, Sweden, United Kingdom). This shows that any efforts to protect road users from injury or death should be given priority. While national and regional road safety programmes help to reduce Poland's fatalities systematically, the effects are from the expectations.

The contemporary approach to safety distinguishes three integrated elements: infrastructure measures, safety management and safety culture. Because of its complexity, the process of safety management needs modern tools to help identify road user risks, estimate and assess road infrastructure safety and select effective safety treatments. The selection of safety measures must be preceded with an understanding of the effects of selected factors on road safety at different levels of management.

Previous national road safety programmes (GAMBIT 1996, GAMBIT 2005) were the basis for developing a new National Road Safety Programme (NRSP) until 2020 in 2012 [1]. As shown by the National Programme's progress Barometer, fatalities have been consistently dropping (with some exceptions, e.g. in 2016) to less than 3,000 deaths annually in 2017. This is, however, above the target (by app. 400 fatalities). Seriously injured remain almost unchanged $(11,000)$ making it significantly higher than the target (app. 3,500). This shows that the treatments are not sufficient and some of them are ineffective.

Designed as the main tools for delivering national road safety strategies, regional and local road safety programmes, apart from sectoral programmes, play an important role in area-specific measures (i.e. in regions, poviats and municipalities) and can help to achieve nearly $50 \%$ of the fatality target. Regional and local programmes are modelled on national programmes. Regional road safety programmes consist of a diagnosis to guarantee an objective perspective on road safety, a strategy with a clear goal and main measures and operational programmes to define the tasks to be delivered by regional institutions and organisations and support for poviat level work [2], [3], [4] [5]. The measures defined in the programmes represented the regional problems and hazards in the following areas: developing road safety structures, road safety education, road traffic enforcement, road infrastructure and rescue. With an extended programme like this, the implementation requires tried and tested, knowledge-based and scientific tools [6]. While the necessary strategic road safety management tools have already been developed [7], tactical and operational road safety management tools are in poor supply in the regions and poviats and poviat capitals.

As an example, road safety is particularly bad in the Łódź region. The region's main road safety problems have been identified along with an analysis of safety based on risk assessment. An estimation was made of the effects of selected factors on road user safety and a fatality forecast was made for different treatment scenarios. 


\section{Literature review}

Modelling and forecasting fatalities at the regional level is a difficult task. Road safety analysis and modelling at the regional level struggle with two problems. Identified as critical for national studies, some of the data are not available at the regional level. As a result, they can hardly be studied for their effect on a region's road safety. With data only available at the national level, national models cannot be applied to the regional level and the results are not likely to be satisfactory. The literature identifies several groups of factors that may have an effect on a region's fatalities. They are demographic, motorization, social, economic, geographic, traffic and infrastructure factors. Demographic factors include population density [8]-[10] or the share of urban population. Motorization and traffic factors include motorization rates, vehicle fleet age and primarily kilometres travelled [11]-[13] which is an important factor increasing the risk of becoming a road fatality. Road infrastructure, its density, quality and diverse functions and functional requirements have an effect on a region's road safety [14]. Economic level and population wealth also matter as well as standards of living and health care provision in a region [7], [15], [16]. Some scientists who have had access to such statistics point to population behaviour such as alcohol consumption or driver age [17], [18]. A frequent finding based on the literature review is that the factors are given varying weights and some of the conclusions are conflicting. While some scientists claim that a factor has a positive effect on safety, others assert to the contrary. This was the case with the unemployment rate. Fournier and Simard [19] showed that the rate increases in connection with less kilometres travelled leading to an accident reduction. Jaeger and Lassare [20], however, did not find that unemployment rate should have a major effect on road safety. Hoxie and Skinner [21] noted that at times of economic recession, the number of fatalities caused by young drivers drops, even if kilometres travelled do not change. This shows that regions may vary vastly and feature different problems that are specific to them.

Depending on the availability of data and the method used, researchers have applied different approaches when analysing factors that affect regional safety levels and when developing relevant safety models. As a rule, because national data are more easily obtained than a country's lower level data, modelling is particularly advanced at this level of aggregation. Multiple factor analyses tend to use the generalised Poisson model [22][24]. Some researchers have used logistic models [25][27], logit models [28] and time series [29], [30]. Because regional data are in poor supply, structural models are used occasionally, including the DRAG, the best known model [31], [32]. The most common way to analyse regional safety differentiation are probabilistic models such as Bayesian methods [33], [34]. While they help to illustrate differences between regions, they do not determine the effects of factors on the safety of regional roads. This article aims to analyse the effect of selected factors on fatalities using the example of the Lódź region.

\section{Level of safety in the Łódź region}

The region of Łódź has some of the worst safety rates. In 2016 there were 4,222 accidents with 5,298 injuries and 214 people killed. Accidents and injuries per 100,000 population (RAR and RIR) place the Łódź region at the bottom of the table among Polish regions with 169 accidents and 215 injuries respectively. Fatalities per 100,000 population (RFR) are at 8.6 which is slightly above the national average (7.9) (Fig. 1).
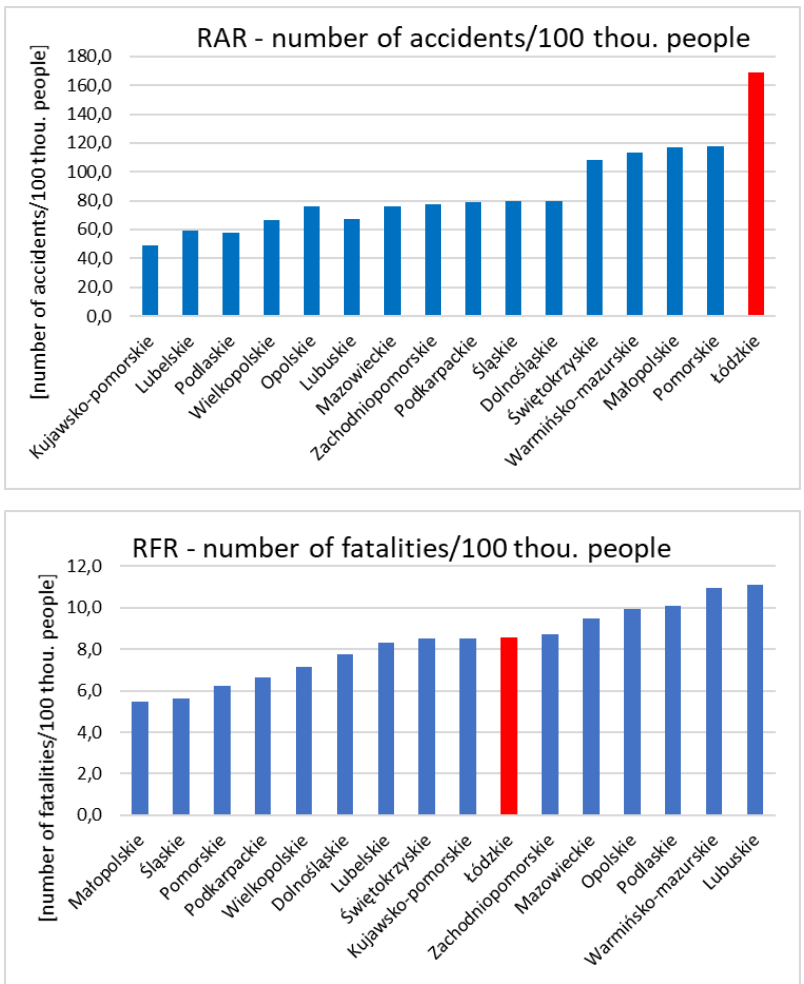

Fig. 1 The position of Łódź region in Poland.

The NRSP's main goal was translated into a regional goal which was to halve fatalities and reduce seriously injured by $40 \%$ by 2020 compared to the baseline year of 2010 . In the Łódź region until 2016 fatalities dropped by $25 \%$. Given the fact that in 2017 fatalities increased to reach 219 , a $50 \%$ reduction is not very likely. The outlooks for seriously injured is very pessimistic. The 2020 target is 575. In 2016 the region recorded as many as 1,426 seriously injured people, an increase compared to 2011 by app. 50\%. Although "a seriously injured victim" is not a well-defined term in Poland, the data suggest that the Łódź region is dealing with a very serious problem.

Analysis of accident types in the Łódź region between 2014 - 2016 shows that most accidents involved side crashes at $38 \%$ of all accidents and hitting a pedestrian at $23 \%$. Fatalities were the highest in accidents involving hitting a pedestrian at $37 \%$ of all fatalities and side crashes at $21 \%$ (Fig. 2).

Part of the Łódź region's safety assessment, societal and individual risk maps were developed by administrative unit (poviats, municipalities) and road network (national and regional roads) for the years 2014 2016. To assess societal risk in the poviats and municipalities measures were used: overall risk (RO) - 
fatalities and seriously injured or serious accidents (accidents involving seriously injured and fatalities) by type: LZCRx (accidents/3 years) and normalised risk $(\mathrm{RN})$ - demographic rate of serious accidents: WDWPx (accidents/100,000 population).
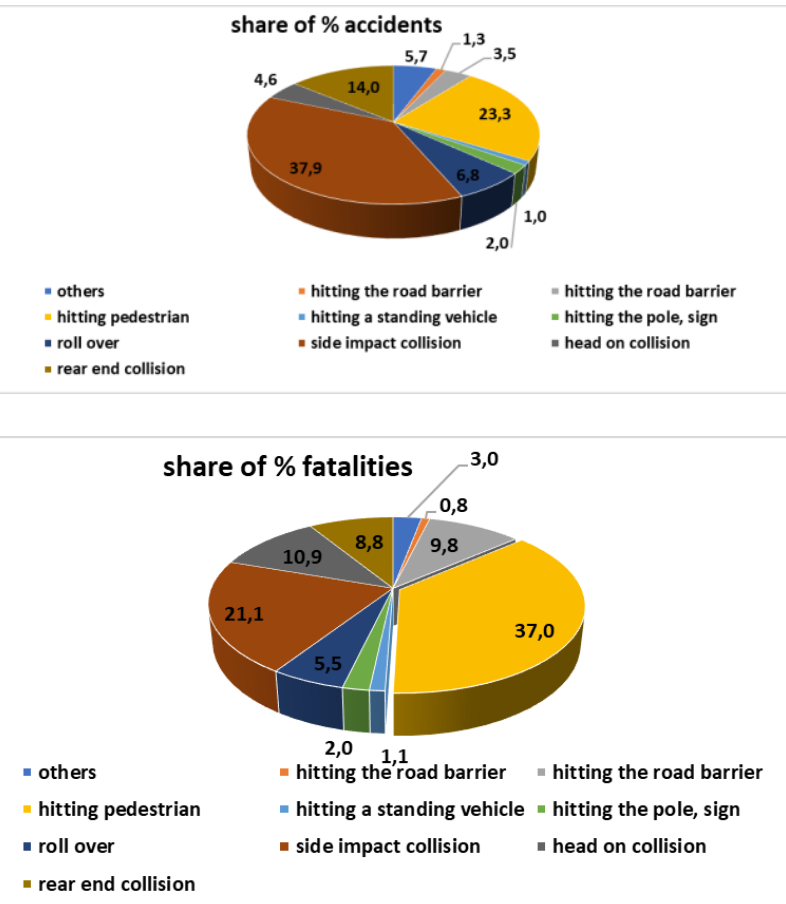

Fig. 2 Types of accidents $2014-2016$.

To assess societal risk on the network of regional and national roads, the serious accident density measure was used (LPW/ $/ \mathrm{km} / 3$ years). To assess individual risk on regional and national roads, the serious accidents concentration measure was used (LWP/m vehicle kilometres $/ 3$ years). This analysis left out societal and individual risk connected with accident costs (Fig. 3 and Fig. 4) [35] Presented below are selected results without a detailed analysis. It is striking that high and very high risk areas and roads represent such a big share, a clear indication of serious road safety problems and the need for treatment.

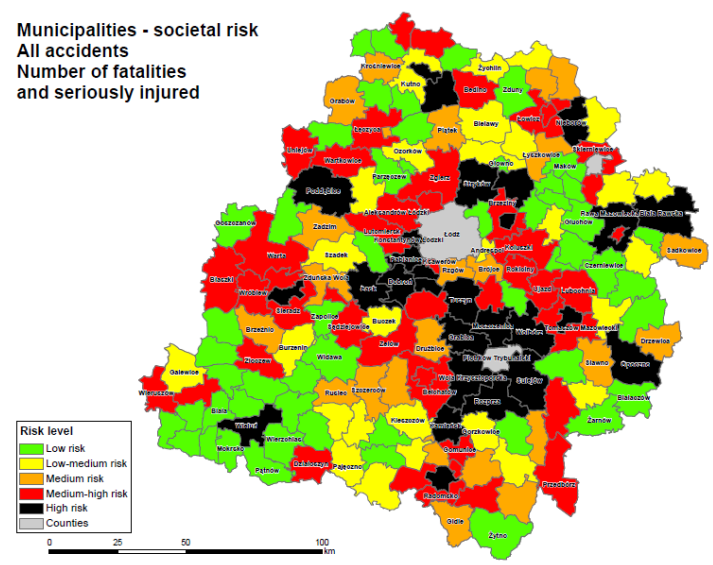

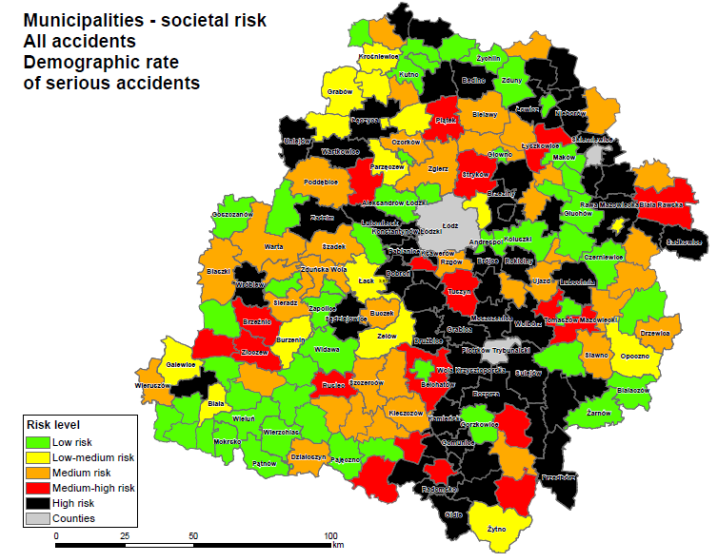
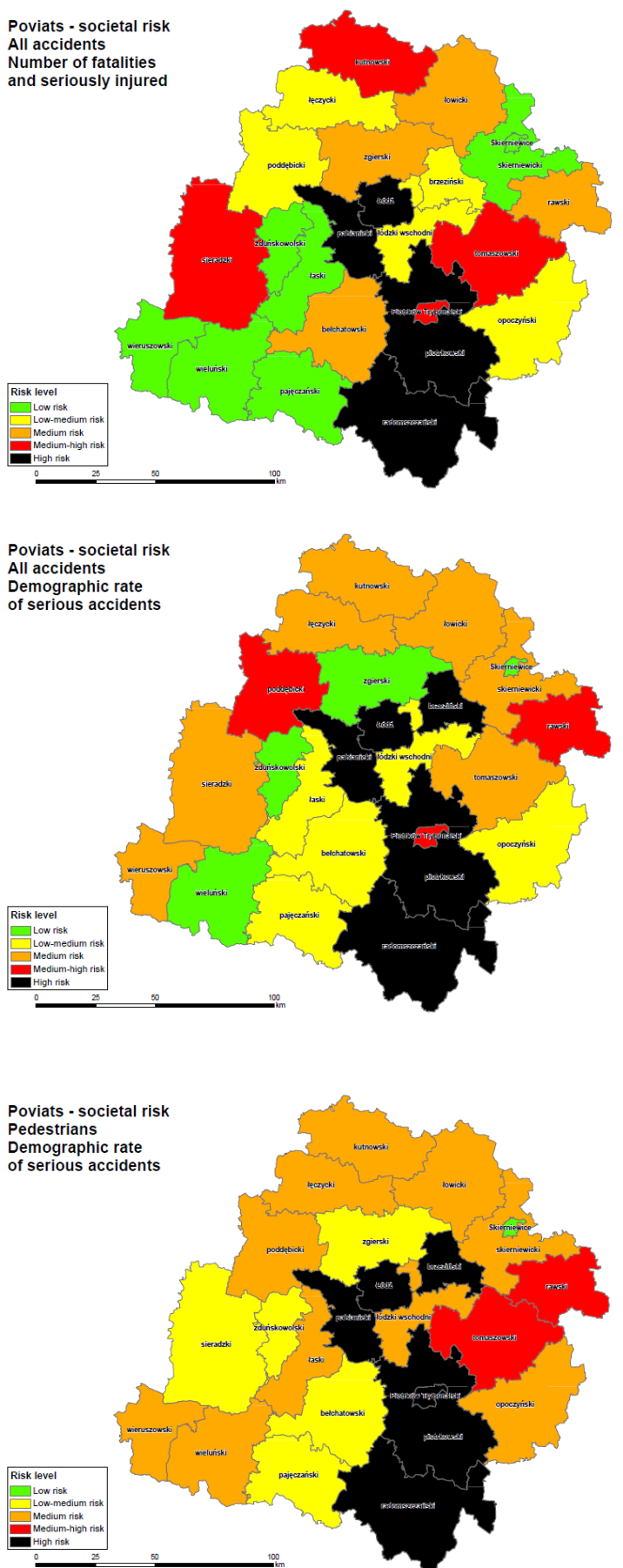

Fig. 3. Maps of area risk for the region of Łódź. 

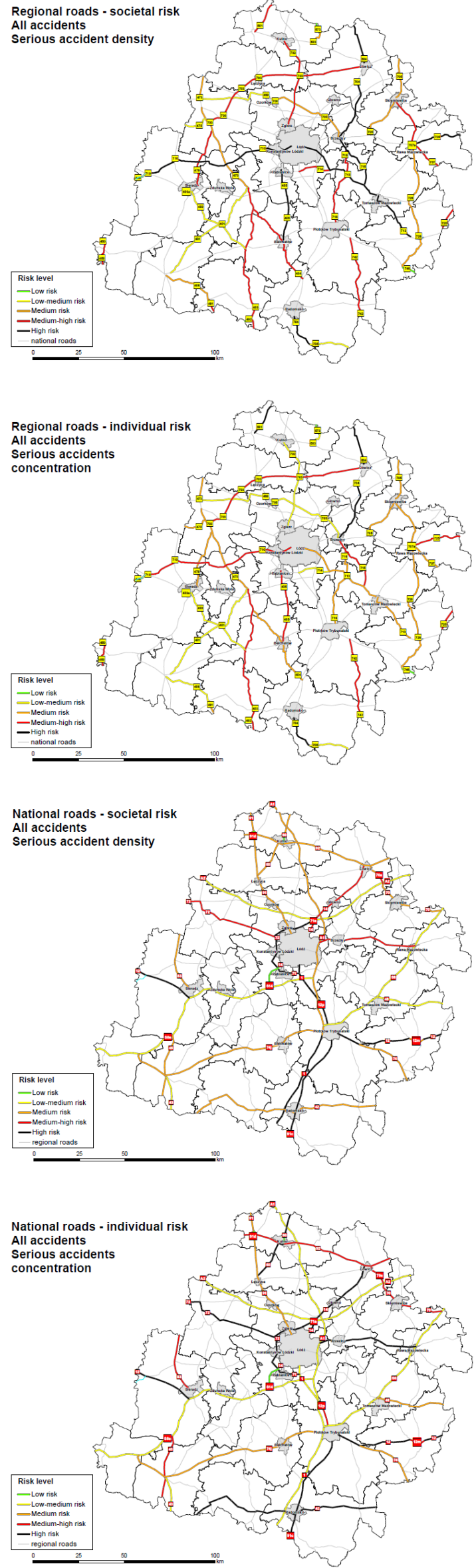

Fig. 4 Risk maps for national and regional roads in the region of Łódź.
By choosing the above measures to assess area risk (poviats and municipalities) we can: compare safety in the municipalities and poviats, monitor progress of improvements and interventions, allocate resources to areas where the risk of becoming involved in a serious accident is the highest and identify the types of accidents that are the biggest problem or the circumstances to include when implementing treatments (e.g. problem of speed, night-time accidents). Thanks to the proposed measures of risk for classifying sections of national and regional roads, we can identify those sections that are most likely to achieve an accident reduction (especially those involving seriously injured and fatalities) and those that are likely to be economically effective in the case specific treatments.

\section{Method}

A study of the literature confirms that modelling road safety at the regional level is difficult which is usually the result of a lack of region-specific data. Efforts to build Poland's regional databases were also affected by this problem. Using data available from Central Statistical Office and Eurostat websites a database was built to represent Polish regions for their demography, population, economy, infrastructure and geography. The generally available data are clearly not enough to characterise transport behaviour on regional roads. Available data are mostly demographic and economic. There are no data about traffic on poviat and municipal roads which represent the majority of the regions' road networks. Some of the variables which the literature considers important for road safety such as alcohol consumption or the time to bring a road accident victim to hospital are not available and not collected either. Unfortunately, attempts to obtain detailed data about a region's transport and social structure fail because the data are not available. Poland's current division into 16 regions has been in place since 1999. In the case of annual analyses, this fact alone generates 18 sets of output data for each region to use for model development. To increase the sample used to estimate the effects of selected factors on road safety measures, a model was built for all of Poland's regions. It was then calibrated for the Łódź region data. Because regions differ on their size and population, fatality models $F_{i}$ will be based on the societal risk model where fatalities are calculated as a product of the likelihood of becoming a victim of an accident in the region $R F R_{i}{ }^{w}$ and the exposure to that risk expressed as the size of the region's population $P_{i}$.

$$
F_{i}^{w}=R F R_{i}^{w} \cdot P_{i}
$$

where:

$P_{i}$ - population of region [100 thou. people],

$R F R_{i}{ }^{{ }}-$model of road fatalities rate in analysed region [fatalities/100 thou. people]

Before work on the mathematical model began, a multidimensional analysis was conducted of the effects of specific factors on the dependent variable being modelled $R F R$. To that end unique Data Mining algorithms were 
used as well as mutual linear connections between independent variables. Using single factor functional analysis, mathematical functions were tested for their ability to describe the observed relations. Once statistically significant modelling variables were selected, work on developing base models $R F R_{i}{ }^{k}$ for data from all regions was undertaken. The next step was to calibrate the models by their product with a modifying function which was made using Łódź regional data $C R F R_{i}{ }^{w}$, It contained factors that are more strongly linked to the variable being modelled in the region than the national average.

$$
R F R_{i}^{W}=R F R_{i}^{k} \cdot C R F R_{i}^{W}
$$

Where:

$R F R_{i}^{k}-$ model of road fatality rate in analysed group of regions [fatalities/100 thou. people],

$C R F R_{i}{ }^{w}$ - regional modification model of road fatality rate

\section{Results and discussion}

As agreed, the first analysis was designed to study the data for their mutual relations and effect on the variable being modelled, i.e. the relative road fatality rate RFR. Figure 5 illustrates the power of collinearity of selected variables within a set of all regions. An explanation of the abbreviations of variables were presented in table 1 .

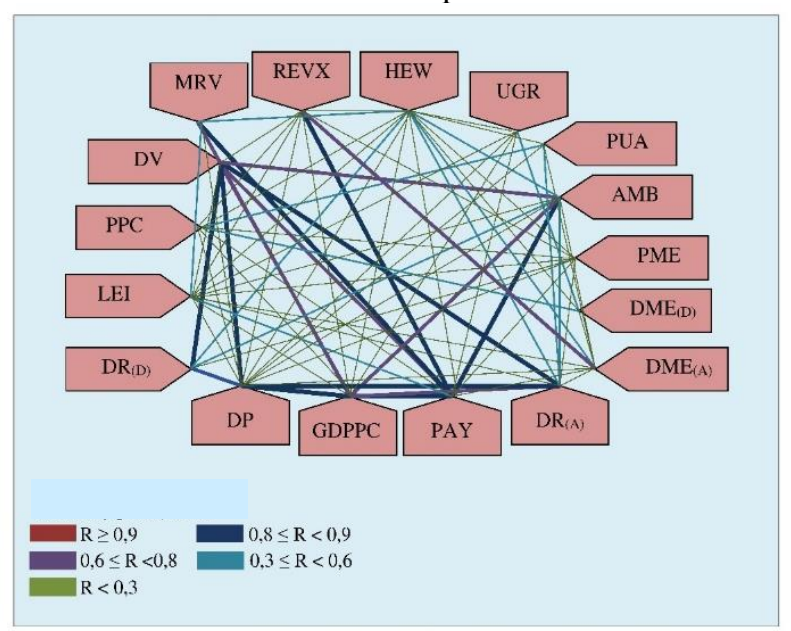

Fig. 5 Correlations between selected independent variables for a Polish database.

Table 1. Explanation of the abbreviations of variables presented in Fig. 5

\begin{tabular}{|l|l|}
\hline Abbreviation & Explanation \\
\hline MRV & $\begin{array}{l}\text { total vehicle motorization rate } \\
\text { [veh./person/year] }\end{array}$ \\
\hline REXV & $\begin{array}{l}\text { expenditure on provincial roads [mln } \\
\text { PLN/km/year] }\end{array}$ \\
\hline HEW & $\begin{array}{l}\text { hospital emergency departments } \\
\text { [number/year] }\end{array}$ \\
\hline UGR & $\begin{array}{l}\text { share of arable land [\%] } \\
\text { in the total area [\%] }\end{array}$ \\
\hline PUA & $\begin{array}{l}\text { emergency medical teams and away } \\
\text { teams [number / year] }\end{array}$ \\
\hline AMB
\end{tabular}

\begin{tabular}{|l|l|}
\hline PME & percentage of highways [\%] \\
\hline DME(D) & $\begin{array}{l}\text { the demographic density of motorways } \\
\text { and express roads [km/1 mln } \\
\text { persons/year] }\end{array}$ \\
\hline DME(A) & density of highways $\left[\mathrm{km} / \mathrm{km}^{2} /\right.$ year] \\
\hline DR(A) & density of roads in total $\left[\mathrm{km} / \mathrm{km}^{2} /\right.$ year] \\
\hline PAY & gross pay [thous. PLN/person/year] \\
\hline GDPPC & $\begin{array}{l}\text { unit gross domestic product per } \\
\text { inhabitant of } \\
\text { [thous.ID/person/year] }\end{array}$ \\
\hline DP & population density [persons $/ \mathrm{km}^{2} /$ year] \\
\hline DR(D) & $\begin{array}{l}\text { population density of roads in total } \\
{[\mathrm{km} / 1 \text { mln persons/year] }}\end{array}$ \\
\hline LEI & the average life expectancy [year] \\
\hline PPC & share of passanger cars [\%] \\
\hline DV & $\begin{array}{l}\text { density of vehicles in total } \\
{\left[\text { veh. } / \mathrm{km}^{2} / \text { year] }\right.}\end{array}$ \\
\hline
\end{tabular}

As we can see in Figure 5 there is a strong colinear relation between the Gross Domestic Product per capita GDPPC and average gross pay PAY. This rate in turn has a strong relation with the amount of funding spent on maintenance of regional roads REXV and the overall rate of vehicle motorization MRV. The results of an independent analysis of factors which are directly linked to the variable RFR are shown in Figure 6. An explanation of the abbreviations of first mentioned variables were presented in table 2 .

Clearly, average gross pay PAY, life expectancy LEI and motorization rate of passenger cars MRPC have a strong effect.

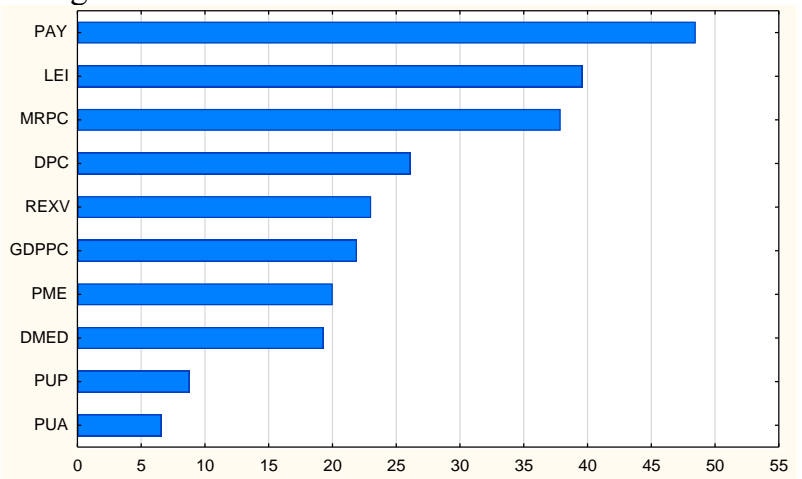

Fig. 6 Relations between variables and RFR for the regional database.

Table 2. Explanation of the abbreviations of first mentioned variables presented in Fig. 6

\begin{tabular}{|l|l|}
\hline Abbreviation & Explanation \\
\hline MRPC & $\begin{array}{l}\text { passenger car rate of motorization } \\
\text { [veh./person/year] }\end{array}$ \\
\hline PUP & share of population living in cities [\%] \\
\hline
\end{tabular}

With linear correlation between the strongly related variables, using them in the model must be done very carefully. Putting them in the same formula may blur the effects they have on RFR. Multiple-factor models can be helpful with assessing the effects of regional characteristics and ultimately with developing tools to support road safety management. By basing the models on data from across all regions, more independent 
variables could be incorporated. If applied to a single region, the variables featured strong collinearity which was no longer the case when applied to a group of many regions. Below is the $\mathrm{RFR}_{\mathrm{i}}^{\mathrm{k}}$ model and how it matches the Łódź region's data (Fig. 7). Because Mazowieckie's safety performance is significantly different from that of the other regions, an additional variable $\mathrm{S}$ was added to ensure that the model is better matched to all of Poland's regions. The model's resulting measure of goodness was $\mathrm{R} 2=67 \%$ and the level was $\mathrm{p}<0.05$.

$$
\begin{gathered}
R F R_{i}^{k}=143.2 \cdot M R P C^{-0.44} \cdot S^{1.94} \cdot D P^{-0.24} \cdot \exp (-0.001 \\
\cdot D M E D(D)-0.64 \cdot A L K)
\end{gathered}
$$

Where:

MRPC - passenger car rate of motorization [veh./person/year]

$\mathrm{S}-$ an additional variable to characterise regions $(\mathrm{S}=1.2$ for Mazowieckie, $S=1$ for the other regions)

DP - population density [person $/ \mathrm{km}^{2} /$ year]

DME(D) - demographic density of motorways and express roads $[\mathrm{km} /$ million people/year $]$

ALK - price of 0.51 of beer [PLN]

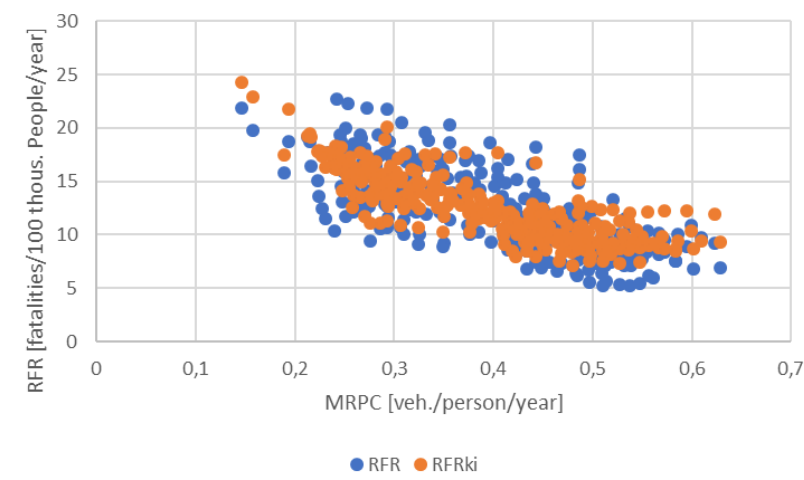

Fig. 7 Real RFR values for all regions and modelled RFRki values depending on the motorization rate of passenger cars MRPC.

As agreed in the method, the model above was calibrated for the Łódź region data producing model 5.2. Its match was $\mathrm{R} 2=87 \%$

$$
\begin{gathered}
R F R_{i}^{w}=201.5 \cdot M R P C^{-0,44} \cdot S^{1,94} \cdot D P^{-0,24} \cdot \exp (-0,005 \\
\cdot D M E D(D)-0,64 \cdot A L K)
\end{gathered}
$$

Fig. 8 shows the arc elasticity rate illustrating the effect of the model's variables on the relative road fatality rate RFR. It shows how a one per cent change in a selected factor affects RFR. Just as demonstrated by other researchers, an increase in population density leads to a fatality rate reduction on the region's roads. It is a similar case for an increasing number of high quality transit roads, i.e. motorways and express roads, that have limited access and are not available to vulnerable users. As the demographic rate of passenger cars MRPC increases, the risk of becoming a road fatality decreases. The final strongly related factor is the average price of alcohol. As the price increases, the RFR was found to decrease. Obviously, the price of alcohol goes hand in hand with economic development and is partly related to the other variables. It does, however, offer some insight into how people behave (frequent alcohol abuse involves drink driving, speeding and other risky behaviour on the roads). This is why the price is included in the model.

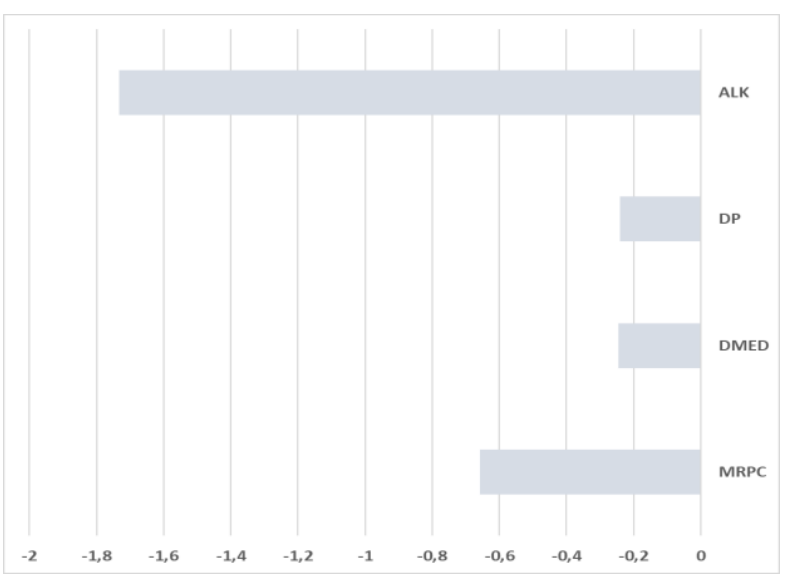

Fig. 8 Arc elasticity chart illustrating the effect of selected independent variables on the relative road fatality rate RFR in model 5.2

In the next step, using forecasts for the Łódź region until 2050 , fatalities are illustrated by different scenarios of how independent variables will change (Fig. 9).

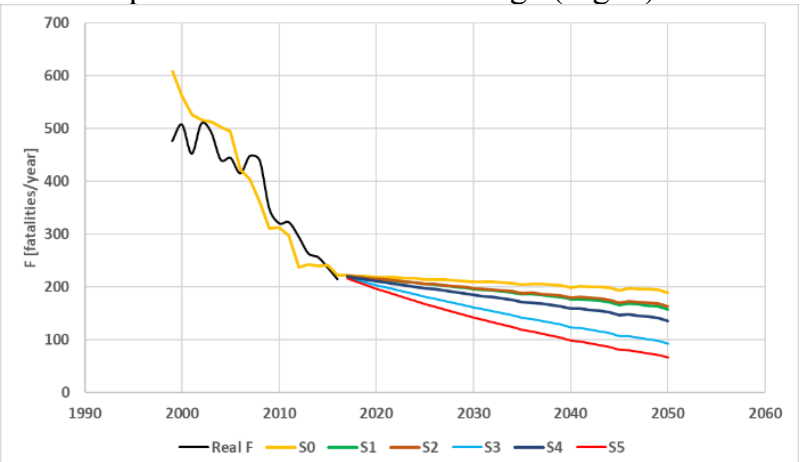

Fig. 9 Forecasted fatalities in the Łódź region for different scenarios.

Table 3. Assumed variability of analysed factors by scenario as presented in Fig. 8

\begin{tabular}{|c|c|c|c|}
\hline Scenario & MRPC & DMED & ALK \\
\hline S0 & const. & const. & const. \\
\hline S1 & const. & $+1 \%$ & const. \\
\hline S2 & $+1 \%$ & const. & const. \\
\hline S3 & const. & const. & $+1 \%$ \\
\hline S4 & $+1 \%$ & $+1 \%$ & const. \\
\hline S5 & $+1 \%$ & $+1 \%$ & $+1 \%$ \\
\hline
\end{tabular}

As forecasted, until 2030 fatalities $\mathrm{F}$ may go down by more than $40 \%$ compared to 2016 and until 2050 that reduction could reach app. $70 \%$. This, however, should involve the construction of new motorways and express roads to eliminate transit traffic through small towns and villages and more frequent driver sobriety checks.

\section{Conclusion and recommendations}

The analysis shows that the regional data collected today do not provide a full insight into the regions' social and 
traffic changes and there is no information on how people travel on the entire road network or on speed violations. Because road spending data has only been collected for a few years, the data could not be used in the model. As we know from the literature, the best indicator of the risk of becoming a road fatality is the number of kilometres travelled. If they contained the variable, models could be more precise in regional road safety management. Yet no such data are available for poviat and municipal road networks.

The Łódź region's safety analysis shows its strong potential for accident and casualty reduction. The models help to estimate the effects of selected factors on road safety and, as a consequence, to take the most effective road safety measures. With new analyses and research, it will be possible to extend the models and use them as tools for regional road safety management.

\section{References}

[1] National Road Safety Council, "National Road Safety Program" 2013.

[2] K. Jamroz, R. Krystek, L. Michalski, and M. Budzynski: "Regional BRD Program GAMBIT Pomeranian. Gdańsk: Foundation for the Development of Civil Engineering" 2002.

[3] M. Budzynski, K. Jamroz, W. Kustra, L. Michalski, and S. Gaca: "Road Infrastructure Safety Management in Poland" IOP Conf. Ser. Mater. Sci. Eng., vol. 245, p. 042066, Oct. 2017.

[4] S. Gaca and M. Kiec: "Speed Management for Local and Regional Rural Roads" Transp. Res. Procedia, vol. 14, pp. 4170-4179, 2016.

[5] J. Chmielewski: "Guidelines for the construction of the it road safety management system" J. Civ. Eng. Environ. Archit., 2016.

[6] K. Jamroz, W. Kustra, M. Budzynski, and J. Zukowska: "Pedestrian protection, speed enforcement and road network structure the key action for implementing Poland 's Vision Zero" Transp. Res. Procedia, vol. 14, pp. 3905-3914, 2016.

[7] K. Jamroz: Method of risk management in road engineering. 2011.

[8] D. E. Clark: "Effect of population density on mortality after motor vehicle collisions" Accid. Anal. Prev., vol. 35, no. 6, pp. 965-971, 2003.

[9] L. Fridstrøm, J. Ifver, S. Ingebrigtsen, R. Kulmala, and L. K. Thomsen: "Measuring the contribution of randomness, exposure, weather, and daylight to the variation in road accident counts" Accid. Anal. Prev., vol. 27, no. 1, pp. 120, Feb. 1995.

[10] O. S. Wegman F, Eksler V, Hayes S, Lynam D, Morsink P: "A comparative study of the development of road safety in the SUNflower 6 countries. Final report" 2005.

[11] D. E. Clark and B. Cushing: "Rural and urban traffic fatalities, vehicle miles, and population density" Accid. Anal. Prev., vol. 36, pp. 967-972, 2004.

[12] M. Pilar, S. González, F. E. Sotos, and Á. T. Ponce: "Impact of provincial characteristics on the number of traffic accident victims on interurban roads in Spain" Accid. Anal. Prev., no. October 2017, pp. 1-12, 2018.

[13] J. Wachnicka, W. Kustra, K. Jamoroz, and M. Budzynski: "Development of Tools for Road Infrastructure Safety Management for the Provinces (Voivodeships) in Poland" in Risk, Reliability and Safety: Innovating Theory and Practice, 2016, pp. 433-440.

[14] T. L. Traynor: "Regional economic conditions and crash fatality rates--a cross-county analysis" J. Safety Res., vol. 39, no. 1, pp. 33-9, Jan. 2008.

[15] E. Kopits and M. Cropper: "Traffic fatalities and economic growth" Accid. Anal. Prev., vol. 37, no. 1, pp. 169-78, Jan. 2005.

[16] B. Strukcinskiene and et al.: "Traffic injury mortality in children in transitional Lithuania - a longitudinal analysis from 1971 to 2005 " Acta Paediatr., vol. 97, no. 3, pp. 358-361, 2008.

[17] R. A. Derrig and et al.: "The effect of population safety belt usage rates on motor vehicle-related fatalities" Accid. Anal. Prev., vol. 34, pp. 101110, 2002.

[18] F. Valent and et al.: "Risk factors for fatal road traffic accidents in Udine" Accid. Anal. Prev., vol. 34, pp. 71-84, 2002.

[19] F. Fournier and R. Simard: "The DRAG-2 Model for Quebec," in Structural Road Accident Models: The International DRAG Family" Oxford: Elsevier Science, 2000, pp. 37-66.

[20] L. Jaeger and S. Lassare: "The TAG-1 Model for France," in Structural Road Accident Models: The International DRAG Family" Oxford: Elsevier Science, 2000, pp. 157-184.

[21] P. D. Hoxie and D. Skinner: "The statistical analysis of socio-economic influences on three groups of high risk fatalities" Washington DC, 1985.

[22] J. Commandeur and S. Lassarre: "Models of road safety developments" Dacota Project, 2013

[23] Noland R.B. and at. al.: "A spatially disaggregate analysis of road casualties in England" Accid. Anal. Prev., vol. 36, no. 6, pp. 973-984, 2004.

[24] G. Yannis and et al.: "Impact of enforcement on traffic accidents and fatalities: A multivariate multilevel analysis" Saf. Sci., vol. 46, pp. 738750, 2008.

[25] J. J. Faraway: "Extending the Linear Model with $R$. Generalized Linear, Mixed Effects and Nonparametric Regression Models", Chapman and Hall/CRC, 2005.

[26] D. Hosmer and et al. "Applied Logistic Regression". New York: Wiley, 2000. 
[27] M. Nowakowska: "Modeling relationships between road features and traffic hazards on nonurban roads". 2013.

[28] R. Sánchez-Mangas and et al.: "The probability of death in road traffic accidents. How important is a quick medical response?" Accid. Anal. Prev., vol. 42, pp. 1048-1056, 2010.

[29] R. Bergel-Hayat and J. Żukowska: "Road Safety Trends at National Level in Europe: A Review of Time-series Analysis Performed during the Period 2000 -12" Transp. Rev., vol. 35, no. 5, pp. 650-671, 2015.

[30] G. Yannis: "Traffic and safety data analysis: from correlation to causation and policy support" National Technical University of Athens, 2015

[31] J. Commandeur and M. Reurings: "International orientation on methodologies for modelling developments in road safety" SWOV Institute for Road Safety Research, 2006.

[32] M. Gaurdy and S. Lassarre: "The Internal DRAG Family". Amsterdam: Pergamon, 2000.

[33] V. Eksler: "Measuring and understanding road safety performance at local territorial level" Saf. Sci., vol. 48, pp. 1197-1202, 2010.

[34] Y. C. MacNab: "A Bayesian hierarchical model for accident and injury surveillance" Accid. Anal. Prev., vol. 35, no. 1, pp. 91-102, Jan. 2003.

[35] W. Kustra, K. Jamroz, and M. Budzynski: "Safety PL- A Support Tool for Road Safety Impact Assessment" in Transportation Research Procedia, 2016, vol. 14. 